\title{
1-D MODELLING AND 3-D SIMULATION OF CONFINED BUBBLE FORMATION AND PRESSURE FLUCTUATIONS DURING FLOW BOILING IN A MICROCHANNEL WITH A RECTANGULAR CROSS-SECTION OF HIGH ASPECT RATIO
}

\author{
S. Gedupudi \\ School of Engineering \& Design, \\ Brunel University, UK \\ Sateesh.Gedupudi@brunel.ac.uk
}

\author{
Y.Q. Zu, \\ School of the Built Environment, \\ University of Nottingham, UK \\ laxyz13@nottingham.ac.uk
}

\author{
T.G. Karayiannis \\ School of Engineering \& Design, \\ Brunel University, UK \\ tassos.karayiannis@brunel.ac.uk
}

\author{
D.B.R. Kenning \\ School of Engineering \& Design, \\ Brunel University, UK \\ David.Kenning@brunel.ac.uk
}

\author{
Y.Y Yan \\ School of the Built Environment, \\ University of Nottingham, UK \\ yuying.yan@nottingham.ac.uk
}

\begin{abstract}
A simple 1-D model with low requirements for computing time is required to investigate parametric influences on the potentially adverse effects of pressure fluctuations driven by confined vapour bubble growth in microchannel evaporative cooling systems operating at high heat fluxes. A model is developed in this paper for the particular conditions of a channel of rectangular cross-section with high aspect ratio with a constant inlet flow rate (zero upstream compressibility). (The model will later be extended to the conditions of finite upstream compressibility that lead to transient flow reversal). Some parametric trends predicted by the model are presented.

The simplifying assumptions in the model are examined in the light of a 3-D simulation by a commercial CFD code, described in an accompanying paper by the same authors. The predictions of pressure changes are in reasonable agreement. It is suggested that the 1-D model will be a useful design tool.
\end{abstract}

\section{INTRODUCTION}

Saturated flow boiling in assemblies of parallel microchannels is a potential method of cooling small devices operating at high heat fluxes, such micro-electronic circuits and fuel cells. Constrained bubble growth may cause fluctuations in pressure that interact with the fundamental processes of bubble nucleation and growth and may also cause flow reversals that disturb the distribution of flow between channels, as discussed in the accompanying paper by $\mathrm{Zu}$ et al. [1]. Flow reversals may be suppressed by large flow resistances at the inlet to each channel, designed to be similar in magnitude to the boiling pressure drop in a channel, without reference to the resistances in the inlet plenum connecting the channels or other sources of upstream compressibility. The pressure fluctuations within channels are not suppressed and observations by collaborators in an investigation of boiling and condensation in microchannels funded by the UK Engineering and Physical Sciences Research Council (private communications [2, 3]) suggest that disturbances may also propagate between channels through the downstream plenum. Parallel channels may also be cross-connected and, in the limit, become equivalent to a single channel with a rectangular cross-section of very large aspect ratio, in which the axial motion of individual large bubbles is poorly defined.

Rational methods of design are required for a wide range of possible conditions that would be impracticable to investigate experimentally. Accurate 3-D CFD simulations with the fine computational grids required to model thin liquid films are expensive in computer time. A simplified approach to 3-D simulation with assumptions derived from experimental observations is described in [1]. Further simplifications of the physics in 1-D models may reduce the requirements for computing time sufficiently to investigate the parametric influences on pressure fluctuations over a wide range of conditions and over sufficiently long periods to model start-up conditions and power transients. 
1-D models for fully-confined bubble flow boiling have been around for a long time. Kew and Cornwell [4] developed a model for the pressure fluctuations required to accelerate liquid slugs trapped between growing bubbles with a uniform rate of heat input per unit length of bubble equal to the wall heat flux, implying the presence of a completely wetted wall. Kenning and Yan [5] measured pressure pulses moving with liquid slugs and confirmed that they were of the order of magnitude predicted in [4]. The Thome et al. [6] heat transfer model (without pressure fluctuations) assumes a uniform rate of heat input corresponding to a wall of negligible thermal capacity but calculates the time required for the liquid film formed round an expanding bubble to dry out: the heat transfer coefficient is greatly reduced in the dry regions, leading to high periodic wall temperatures. The Shafri et al. [7] model for oscillatory heat pipes considers long confined bubbles with a finite liquid film at each end, moving between wall regions at uniform superheat or subcooling. The Wen et al. [8] model for bubble growth in a uniformly superheated capillary tube without inlet flow considers transient conduction in the liquid film and the wall, at a considerable additional cost in computing time. Comparison with experimental data was improved by assuming that the film length was limited, not by evaporation but by roll-up due to capillary forces at finite contact angles; steady-flow estimates of viscous stresses in the accelerating liquid slugs were found to be incompatible with the data. All the models [4, 6, 7, 8] assume uniformity of temperature and pressure within a bubble, which cannot hold in very elongated bubbles as transition to annular flow is approached. In $[4,6,8]$ the vapour and liquid-vapour interface are assumed to be at the saturation temperature corresponding to the instantaneous bubble pressure.

The new feature of the 1-D model presented in Section 2 of this paper is that confinement is assumed to occur in two stages appropriate to growth in a channel in a channel of rectangular cross-section of high aspect ratio $r=w / h$, suggested by the experimental observations in [1] in a channel with three heated sides and an adiabatic window on one major side $w$. In the first stage of partially confined growth, the bubble has depth $h$ and equal width and length $b(t)<w$. In the second stage of fully confined growth, the bubble fills the channel cross-section (except for thin liquid films) and only its length $\mathrm{z}(\mathrm{t})$ increases with time. Two versions of the equations are presented, one with constant vapour density (suitable for small changes in absolute pressure during bubble growth), the other with saturated vapour density corresponding to the instantaneous pressure. The other features of the model are kept as simple as possible: growth of a single bubble due to constant wall heat flux, with constant liquid flow entering the channel and constant exit pressure, viscous stresses in the liquid negligible compared to inertial stresses. More advanced features, including finite upstream compressibility leading to flow reversal, will be described in subsequent papers.

All 1-D models have problems with the specification of the initial values of various time derivatives that depend on the precise nature of bubble growth from a nucleus prior to confinement. During unconfined growth, shortly after disturbance of the meta-stability of the nucleus, there is a short period of inertially controlled growth [9]. Kandlikar [10] suggested that a pressure spike associated with nucleation could cause flow reversal. Pressure spikes were not detected in the experiments in $[5,8]$ in relatively large channels with crosssectional dimensions of the order of $1 \mathrm{~mm}$, but this is not to say that they do not occur in much smaller channels. The specification of initial conditions was discussed in $[8,11]$ and is considered further in Section 4 of this paper. This raises the general point that the simplifying assumptions in 1-D models have limitations on their ranges of validity that should be reexamined for each new application. Some parametric trends predicted by the constant vapour density model are presented in Section 2. In Section 3, the predictions of pressure transients and other fluid mechanical aspects of the new model are compared with the more detailed modelling in the simplified 3D CFD simulation introduced in [1]. Modifications to the 1-D model incorporating properties variation are presented in Section 4

\section{NOMENCLATURE}

A Heat transfer area $\left(\mathrm{m}^{2}\right)$ for bubble.

b The size $(\mathrm{m})$, width and breadth, of the partially-confined bubble.

$\mathrm{c}_{\mathrm{p}} \quad$ Specific heat

$\mathrm{h} \quad$ Bubble height, equal to channel depth (h).

h Enthaply $(\mathrm{J} / \mathrm{kg})$.

$\mathrm{h}_{\mathrm{lv}} \quad$ Latent heat of vaporisation $(\mathrm{J} / \mathrm{kg})$.

$\mathrm{L}_{1}, \mathrm{~L}_{2}$ Distance (m) of nucleation site from channel inlet and outlet respectively.

M Momentum $(\mathrm{kg} \mathrm{m} / \mathrm{s})$.

$\dot{\mathrm{m}}$ Mass flow rate $(\mathrm{kg} / \mathrm{s})$.

$\mathrm{m} \quad$ Mass $(\mathrm{kg})$.

$\mathrm{p}_{1}, \mathrm{p}_{2} \quad$ Channel (control volume) inlet and outlet pressures $(\mathrm{Pa})$ respectively.

q Heat flux $\left(\mathrm{W} / \mathrm{m}^{2}\right)$.

Q Heat transfer ( $\mathrm{J})$.

r Channel aspect ratio.

$\mathrm{t} \quad$ Time (s).

$t_{c} \quad$ Time (s) required for full confinement

$t^{\prime} \quad t-t_{c}$, time scale (s) for fully-confined bubble growth.

$\mathrm{T}$ Temperature $(\mathrm{K})$.

$\mathrm{u} \quad$ Internal energy $(\mathrm{J} / \mathrm{kg})$.

$\mathrm{U} \quad$ Total internal energy $(\mathrm{J})$.

$\mathrm{U}_{1} \quad$ Channel inlet velocity $(\mathrm{m} / \mathrm{s})$ or liquid velocity at the upstream end of the bubble.

$\mathrm{U}_{2} \quad$ Channel outlet velocity $(\mathrm{m} / \mathrm{s})$ or liquid velocity at the downstream end of the bubble.

v Specific volume $\left(\mathrm{m}^{3} / \mathrm{kg}\right)$.

V Bubble volume $\left(\mathrm{m}^{3}\right)$.

$\dot{\mathrm{V}} \quad$ Bubble volume growth rate $\left(\mathrm{m}^{3} / \mathrm{s}\right)$.

w Channel width (m).

$\mathrm{x}_{\mathrm{u}}, \mathrm{x}_{\mathrm{d}}$ Locations $(\mathrm{m})$ of the upstream and downstream ends of the bubble from the channel inlet respectively.

$\mathrm{z} \quad$ Length $(\mathrm{m})$ of the bubble in fully-confined bubble growth.

\section{Greek Symbols}

$$
\begin{array}{ll}
\tau & \text { Time constant }(\mathrm{s}), \frac{\rho_{\mathrm{v}} \mathrm{h}_{\mathrm{lv}} \mathrm{h}}{\mathrm{q}} \\
\rho & \text { Density }\left(\mathrm{kg} / \mathrm{m}^{3}\right) .
\end{array}
$$

Subscripts and Superscripts 
1 Liquid.

Vapor.

Saturated.

confinement (when full confinement begins).

\section{1-D MODEL FOR CONFINED GROWTH, NO UPSTREAM COMPRESSIBILITY}

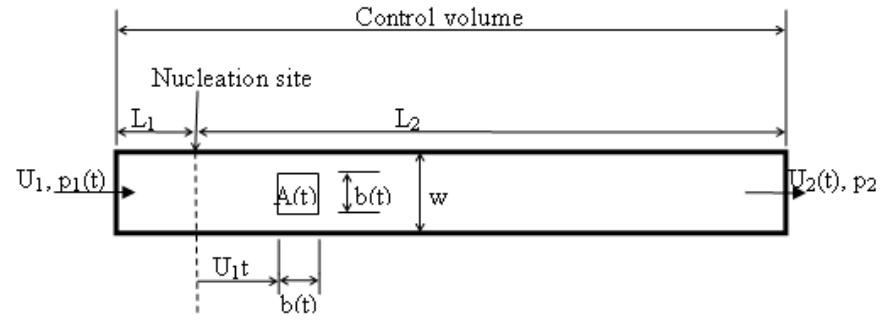

a. Partially-confined bubble growth.

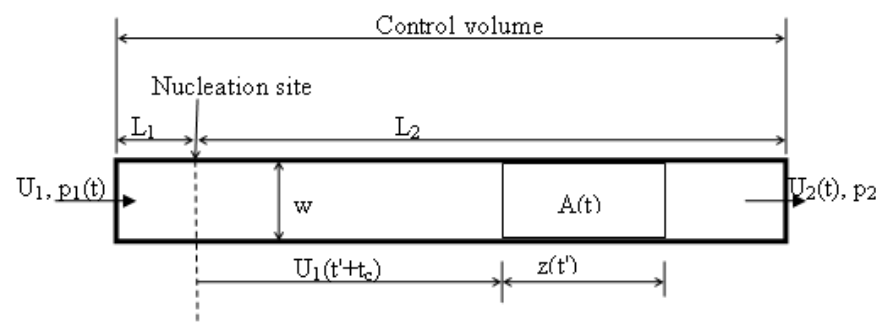

b. Fully-confined bubble growth

Fig. 1. Bubble growth

The channel is rectangular, of width $\mathrm{w}$, depth $\mathrm{h}<<\mathrm{w}$ and length $\mathrm{L}_{1}+\mathrm{L}_{2}$. Heat input is on one side $\mathrm{w}$ with an adiabatic window on the other side $\mathrm{w}$ and negligible heat input on sides $\mathrm{h}$ (for high aspect ratio, w/h). A single nucleation site is assumed, located at $\mathrm{L}_{1}$ from the inlet and $\mathrm{L}_{2}$ from the outlet, as shown in figures $1 \mathrm{a}$ and $1 \mathrm{~b}$. Inlet compressibility is absent so the inlet velocity $U_{1}$ is constant.

\subsection{Partially-confined growth ( PC )}

In a high aspect ratio channel, it takes some time for the bubble to grow to the channel width $\mathrm{w}$ as it moves along the channel. This is defined as partially-confined growth, in which the bubble is confined fully along the depth $h$, except for very thin liquid films between the bubble and the surfaces $\mathrm{w}$.

Partially-confined growth is assumed for the growth from A $=\mathrm{h}^{2}$ at time $\mathrm{t}=0$, through $\mathrm{A}=[\mathrm{b}(\mathrm{t})]^{2}$ to $\mathrm{A}=\mathrm{w}^{2}$. The earliest stage of unconfined growth from a nucleus with dimensions $<<\mathrm{h}$ is neglected.

Neglecting the volume of the thin liquid films on sides $\mathrm{W}$, the volume of the bubble $\mathrm{V}(\mathrm{t})$ is $\mathrm{hA}(\mathrm{t})$. Assuming constant heat flux $\mathrm{q}$ through the single contact area $\mathrm{A}$ and neglecting the change of $\rho_{\mathrm{v}}$ and $h_{\mathrm{lv}}$ with pressure, the heat balance equation for bubble growth is given by

$\rho_{\mathrm{v}} \mathrm{h}_{\mathrm{lv}} \mathrm{h} \frac{\mathrm{dA}}{\mathrm{dt}}=\mathrm{qA}$
Let $b^{2}$ be the area of the bubble at any instant of time, then $\rho_{\mathrm{v}} \mathrm{h}_{\mathrm{lv}} \mathrm{h} 2 \frac{\mathrm{db}}{\mathrm{dt}}=\mathrm{qb}$

The initial condition at time $\mathrm{t}=0$ is $\mathrm{b}=\mathrm{h}$. Then

$\mathrm{b}=h \mathrm{e}^{\mathrm{t} /(2 \tau)}$

where $\tau=\frac{\rho_{\mathrm{v}} \mathrm{h}_{\mathrm{lv}} \mathrm{h}}{\mathrm{q}}$

The inlet velocity $U_{1}$ is constant. The velocity at the downstream of bubble is $U_{2}(t)$, which varies with time as the bubble grows.

$$
\mathrm{U}_{2}=\mathrm{U}_{1}+\frac{\mathrm{d}\left(\frac{\mathrm{V}}{\mathrm{wh}}\right)}{\mathrm{dt}}=\mathrm{U}_{1}+\frac{\mathrm{d}\left(\frac{\mathrm{b}^{2}}{\mathrm{w}}\right)}{\mathrm{dt}}
$$

Substituting ( 2 ) in ( 4 ) gives

$$
\mathrm{U}_{2}=\mathrm{U}_{1}+\left(\frac{\mathrm{h}^{2}}{\mathrm{w} \tau}\right) \mathrm{e}^{\mathrm{t} / \tau}
$$

Momentum within the control volume defined by the channel is given by

$$
\begin{aligned}
M= & w h \rho_{1} U_{1}\left(L_{1}+U_{1} t\right)+w h \rho_{1} U_{2}\left(L_{2}-U_{1} t-b\right) \\
& +h b\left[\rho_{1}(w-b)+\rho_{v} b\right]\left(\frac{U_{1}+U_{2}}{2}\right)
\end{aligned}
$$

in which the first term represents the momentum associated with the upstream liquid, the second term represents the momentum associated with the accelerated liquid at the downstream side of the bubble, and the third term represents the momentum associated with the bubble and liquid along side it, with velocity assumed to be $\left(\mathrm{U}_{1}+\mathrm{U}_{2}\right) / 2$.

The pressure difference across the control volume, neglecting friction, is given by

$$
\mathrm{p}_{1}(\mathrm{t})-\mathrm{p}_{2}=\left(\rho_{1} \mathrm{U}_{2}^{2}-\rho_{1} \mathrm{U}_{1}^{2}\right)+\frac{1}{w h} \frac{\mathrm{dM}}{\mathrm{dt}}
$$

Substituting ( 2), ( 5 ) and ( 6 ) in ( 7 ) gives

$$
\frac{p_{1}(t)-p_{2}}{\rho_{1}}=\left(\frac{h^{2}}{w \tau^{2}} e^{t / \tau}\right)\left[\begin{array}{l}
L_{2}-U_{1}\left(t-\frac{\rho_{v} \tau}{\rho_{1}}\right) \\
-\frac{3}{4} h e^{t /(2 \tau)}+\frac{\rho_{v}}{\rho_{1}} \frac{h^{2}}{w} e^{t / \tau}
\end{array}\right]
$$

The time required for confinement, $t_{c}$, from $b=h($ at time $t=0)$ to $b=w$ ( at time $t=t_{c}$ ), is obtained from equation ( 2 ) as

$$
\mathrm{t}_{\mathrm{c}}=2 \tau \ln (\mathrm{w} / \mathrm{h})
$$

Location of the upstream end of the bubble from the channel entrance is given by

$$
\mathrm{x}_{\mathrm{u}}=\mathrm{L}_{1}+\mathrm{U}_{1} \mathrm{t}
$$

Location of the downstream end of the bubble from the channel entrance is given by

$$
x_{d}=L_{1}+U_{1} t+b=L_{1}+U_{1} t+h e^{t /(2 \tau)}
$$

\subsection{Fully-confined growth (FC)}

Fully-confined bubble growth commences from the time at which $b=w$. Let $t^{\prime}$ be the new time scale for the fully-confined growth.

$$
\mathrm{t}^{\prime}=\mathrm{t}-\mathrm{t}_{\mathrm{c}}, \text { with } \mathrm{A}=\mathrm{w}^{2} \text { at } \mathrm{t}^{\prime}=0 .
$$


Let $\mathrm{z}\left(\mathrm{t}^{\prime}\right)$ be the length of the fully-confined bubble at any instant of time $t^{\prime}$.

Neglecting the volume of the liquid film on sides $w$, and neglecting the change of $\rho_{\mathrm{v}}$ and $\mathrm{h}_{\mathrm{lv}}$ with pressure, and assuming constant heat flux q, the heat balance equation for bubble growth is given by

$$
\rho_{\mathrm{v}} \mathrm{h}_{\mathrm{lv}} \mathrm{h} \frac{\mathrm{dz}}{\mathrm{dt}^{\prime}}=\mathrm{qz}
$$

The above equation, on integration, and substituting $\mathrm{z}=\mathrm{w}$ at $\mathrm{t}^{\prime}$ $=0$, yields

$$
\mathrm{z}=\mathrm{we}^{\mathrm{t}^{\prime} / \tau}
$$

where time constant $\tau=\frac{\rho_{\mathrm{v}} \mathrm{h}_{\mathrm{lv}} \mathrm{h}}{\mathrm{q}}$

The exponential growth is consistent with the experimental observations reported in [1].

$$
\mathrm{U}_{2}=\mathrm{U}_{1}+\frac{\mathrm{dz}}{\mathrm{dt}^{\prime}}=\mathrm{U}_{1}+\left(\frac{\mathrm{w}}{\tau}\right) \mathrm{e}^{\mathrm{t}^{\prime} / \tau}
$$

Momentum within the channel control volume is given by

$$
\begin{aligned}
\mathrm{M}= & \operatorname{wh} \rho_{1} \mathrm{U}_{1}\left(\mathrm{~L}_{1}+\mathrm{U}_{1}\left(\mathrm{t}^{\prime}+\mathrm{t}_{\mathrm{c}}\right)\right) \\
& +w h \rho_{1} \mathrm{U}_{2}\left(\mathrm{~L}_{2}-\mathrm{U}_{1}\left(\mathrm{t}^{\prime}+\mathrm{t}_{\mathrm{c}}\right)-\mathrm{z}\right) \\
& +\rho_{\mathrm{v}} w h z\left(\frac{\mathrm{U}_{1}+\mathrm{U}_{2}}{2}\right)
\end{aligned}
$$

Pressure drop across the control volume, neglecting the friction, is given by expression ( 7 ).

Substituting ( 13), ( 15 ) and ( 16 ) in ( 7 ) gives

$$
\begin{aligned}
& \frac{p_{1}(t)-p_{2}}{\rho_{1}}=\left(\frac{w}{\tau^{2}} e^{t^{\prime} / \tau}\right)\left[L_{2}-U_{1}\left(t^{\prime}+t_{c}\right)-w e^{t^{\prime} / \tau}\right] \\
& +\left(\frac{\rho_{v}}{\rho_{1}}\right)\left[U_{1}\left(\frac{w}{\tau} e^{t^{\prime} / \tau}\right)+\left(\frac{w}{\tau}\right)^{2} e^{2 t^{\prime} / \tau}\right]
\end{aligned}
$$

Location of the upstream end of the bubble from the channel entrance is given by,

$$
\mathrm{x}_{\mathrm{u}}=\mathrm{L}_{1}+\mathrm{U}_{1}\left(\mathrm{t}^{\prime}+\mathrm{t}_{\mathrm{c}}\right)
$$

Location of the downstream end of the bubble from the channel entrance is given by

$$
\mathrm{x}_{\mathrm{d}}=\mathrm{L}_{1}+\mathrm{U}_{1}\left(\mathrm{t}^{\prime}+\mathrm{t}_{\mathrm{c}}\right)+\mathrm{z}=\mathrm{L}_{1}+\mathrm{U}_{1}\left(\mathrm{t}^{\prime}+\mathrm{t}_{\mathrm{c}}\right)+\mathrm{we}^{\mathrm{t}^{\mathrm{t} / \tau}}
$$

Expression (17) is valid until the downstream end of the bubble reaches the channel outlet.

From expressions ( 8 ) and ( 17 ), there is a step decrease in $\left(p_{1}-p_{2}\right)$ of $\rho_{1}(w / \tau)^{2} / 4$ at the instant of confinement, and therefore the model needs some improvement to allow smooth transition from partially-confined growth to fully-confined growth.

Results for water are shown in figures $2-5$ for $\mathrm{p}_{2}=1$ bar, with properties corresponding to $\mathrm{p}_{2}$ ( i.e. neglecting their change with pressure $p_{1}$ inside the bubble ).

Figure 2 shows the effect of the location of the nucleation site. With the decrease of $\mathrm{L}_{1}$ ( or the increase of $\mathrm{L}_{2}$ ), the pressure difference increases, as the initial amount of accelerated liquid downstream of the bubble increases. With time, the acceleration increases but the amount of accelerated liquid on the downstream side of the bubble decreases, so that the pressure drop reaches a maximum value and then declines.
The saturation temperature scale corresponding to the inlet and bubble pressure $p_{1}$ is also shown in figure 2. Figure 3 shows the locations of the upstream and downstream ends of the bubble from the channel inlet, the difference being the length of the bubble.

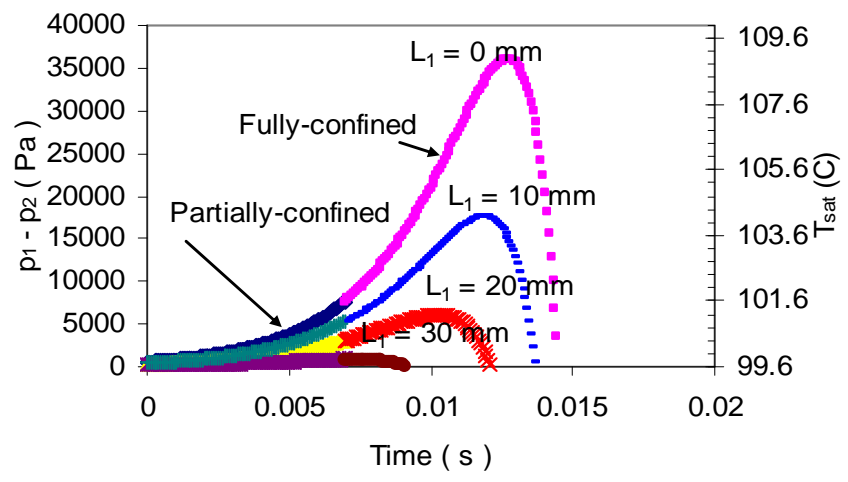

Fig. 2: Transient pressure drop for different locations of the nucleation site from inlet. $\mathrm{q}=200 \mathrm{~kW} / \mathrm{m}^{2}, \mathrm{U}_{1}=0.7$ $\mathrm{m} / \mathrm{s}, \mathrm{w}=1.5 \mathrm{~mm}, \mathrm{~h}=0.38 \mathrm{~mm}, \mathrm{~L}_{1}+\mathrm{L}_{2}=40 \mathrm{~mm}$.

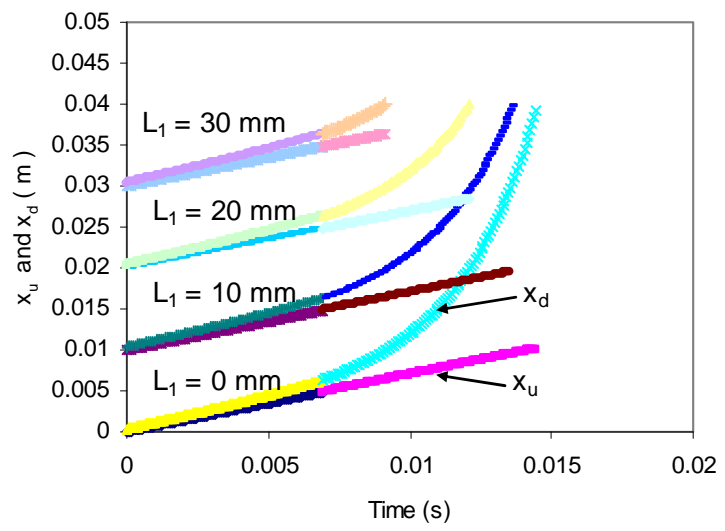

Fig. 3: Bubble locations for different $\mathrm{L}_{1} . \mathrm{q}=200 \mathrm{~kW} / \mathrm{m}^{2}$, $\mathrm{U}_{1}=0.7 \mathrm{~m} / \mathrm{s}, \mathrm{w}=1.5 \mathrm{~mm}, \mathrm{~h}=0.38 \mathrm{~mm}$, $\mathrm{L}_{1}+\mathrm{L}_{2}=40 \mathrm{~mm}$.

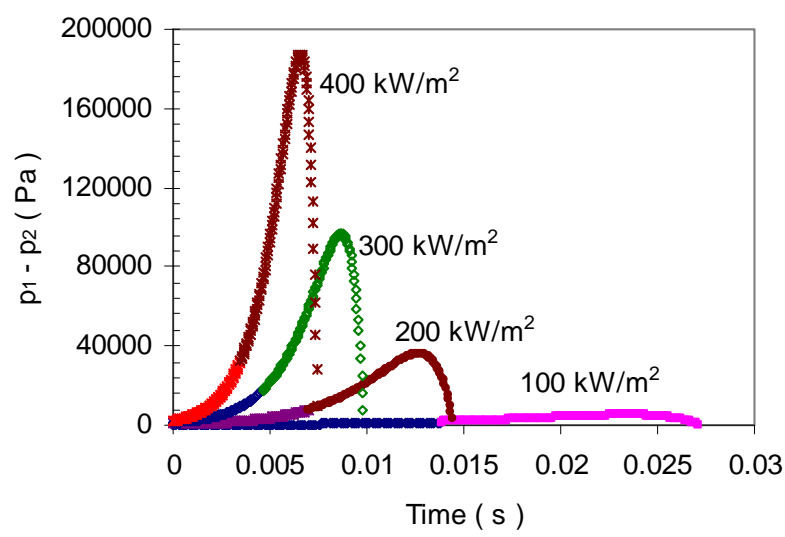

Fig. 4: Transient pressure drop for different q. $U_{1}=0.7 \mathrm{~m} / \mathrm{s}$, $\mathrm{L}_{1}=0 \mathrm{~mm}, \mathrm{~L}_{2}=40 \mathrm{~mm}, \mathrm{w}=1.5 \mathrm{~mm}, \mathrm{~h}=0.38 \mathrm{~mm}$.

Figure 4 shows that with the increase of the heat flux, the pressure drop increases, caused by the increase in the acceleration of the liquid. The peak pressure difference is about 
1.9 bar for $400 \mathrm{~kW} / \mathrm{m}^{2}$. Very high pressure drop also means that the variation of vapour density with the pressure (by a factor of 2.7 in this example) has to be considered in the model for pressure drop. Constant vapour density (corresponding to $1 \mathrm{bar}$ ) may overestimate the pressure drop.

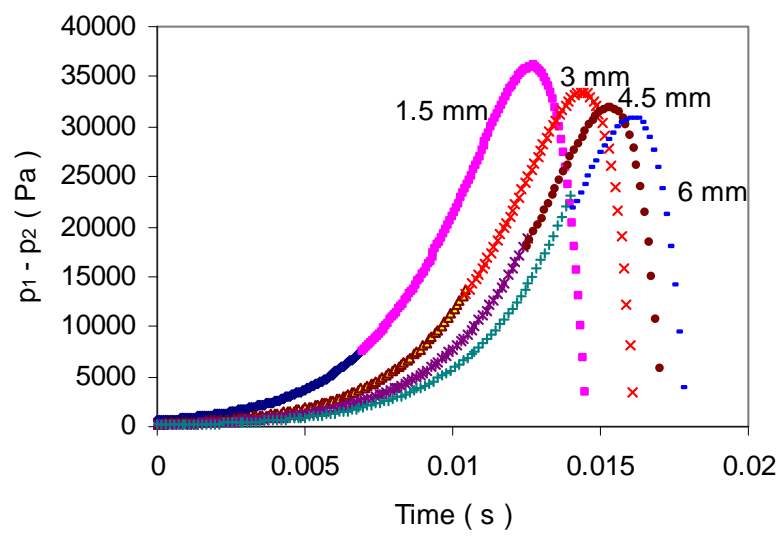

Fig. 5: Transient pressure drop for different $\mathrm{w} . \mathrm{U}_{1}=0.7 \mathrm{~m} / \mathrm{s}$, $\mathrm{L}_{1}=0 \mathrm{~mm}, \mathrm{~L}_{2}=40 \mathrm{~mm}, \mathrm{~h}=0.38 \mathrm{~mm}, \mathrm{q}=200 \mathrm{~kW} / \mathrm{m}^{2}$.

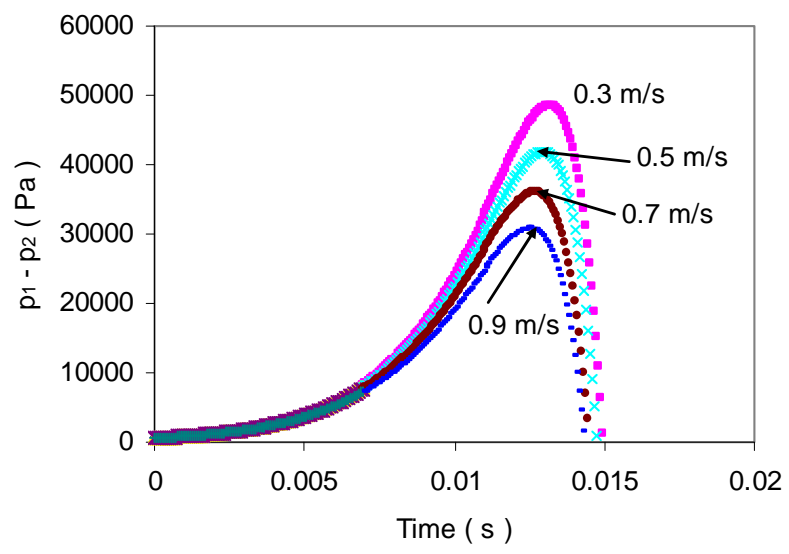

Fig. 6: Transient pressure drop for different $U_{1} . w=1.5 \mathrm{~mm}$, $\mathrm{L}_{1}=0 \mathrm{~mm}, \mathrm{~L}_{2}=40 \mathrm{~mm}, \mathrm{~h}=0.38 \mathrm{~mm}, \mathrm{q}=200 \mathrm{~kW} / \mathrm{m}^{2}$.

Figure 5 shows the pressure drop for different channel widths - ranging from $1.5 \mathrm{~mm}$ ( hydraulic diameter $0.61 \mathrm{~mm}$ ) to $6 \mathrm{~mm}$ (hydraulic diameter $0.71 \mathrm{~mm}$ ) for the same minor dimension $h=0.38 \mathrm{~mm}$. The effect is relatively small, provided $\mathrm{w} \gg \mathrm{h}$. At the time of full confinement, there is a sudden pressure decrease between partially-confined growth and fullyconfined growth) of about $85 \mathrm{~Pa}$ for $1.5 \mathrm{~mm}$ width, and $1346 \mathrm{~Pa}$ for $6 \mathrm{~mm}$ width, so the model needs some improvement to allow a smooth transition. With increasing channel inlet velocity, figure 6 , the amount of the accelerated liquid slug decreases, resulting in a decrease in the pressure drop.

Both the partially-confined and fully-confined models assume that only part of the heat flux from the wall causes evaporation. The rest must cause superheating of the liquid. At present, heat transfer from the bulk liquid to the bubble is neglected. Unlike the Thome et al. heat transfer model [6], local time-averaged phase equilibrium is not assumed.

\section{COMPARISON OF 1-D MODEL AND 3-D SIMULATION}

A full 3D numerical simulation of confined bubble growth during flow boiling in a mini-micro channel based on the

volume of fluid (VOF) method [12] available in the CFD commercial code FLUENT 6 has been presented in [1]. To validate the 1-D analytical results, the 3-D simulations are performed with negligible viscous forces and surface tension stresses, in order to be consistent with the 1D model. The volume of the bubble is specified on the basis of analytical results; and a transient vapour mass flow rate, based on the analytical results, is specified at the bubble-wall interface to approximate the bubble growth.

Uniform $500 \times 100 \times 40$ hexahedral elements are used for meshing the channel. A grid sensitivity study was firstly performed for the early stages of development of the flow. It was found that the pressure different between the inlet and outlet of the channel, when $\mathrm{t}=0.005$ and $0.007 \mathrm{~ms}$, changes less than $1.98 \%$ and $2.02 \%$ respectively when the grid size was changed from $500 \times 100 \times 40$ to $1000 \times 200 \times 80$. To save the computational resources, the mesh of $500 \times 100 \times 40$ was used for this simulations. The time step size was set at $1 \times 10^{-6} \mathrm{~s}$. At each time step, the solution was assumed to converge when normalized residuals of the continuity and all other variables are less than $10^{-3}$. In addition, the maximum number of iterations per time step was set at 20.

For partially-confined bubble growth, the bubble volume at a specified time $t$ is given by

$$
V(t)=h\left(x_{d}-x_{u}\right)^{2}=h^{3} e^{t / \tau}
$$

The rate of volume growth at the time $t$ is

$$
\dot{V}(t)=h^{3} e^{t / \tau} / \tau
$$

For fully-confined bubble growth, the bubble volume at a specified time $\mathrm{t}$ is given by

$$
V(t)=h w\left(x_{d}-x_{u}\right)=h w^{2} e^{\left(t-t_{c}\right) / \tau}
$$

Therefore, the rate of volume growth at the time $t$ is

$$
\dot{V}(t)=h w^{2} e^{\left(t-t_{c}\right) / \tau} / \tau
$$

As a result, the vapour mass flow rate used in the present simulation is specified by

$$
\dot{m}(t)=\dot{V}(t) \rho_{v}=\left\{\begin{array}{cc}
h^{3} \rho_{v} e^{t / \tau} / \tau ; & t \leq t_{c} \\
h w^{2} \rho_{v} e^{\left(t-t_{c}\right) / \tau} / \tau ; & t>t_{c}
\end{array} .\right.
$$

The comparison of 1-D model and 3-D simulation is shown in Figure 7 for the case of $U_{1}=0.7 \mathrm{~m} / \mathrm{s}, \mathrm{q}=200 \mathrm{~kW} / \mathrm{m}^{2}, \mathrm{w}=1.5 \mathrm{~mm}$, $\mathrm{h}=0.38 \mathrm{~mm}, \mathrm{~L}_{1}=0 \mathrm{~mm}$ and $\mathrm{L}_{2}=40 \mathrm{~mm}$. The fluid (water) 
properties used in the simulation are the same as those used in the 1-D model. The trend of pressure development with time obtained by both methods agrees quite well, although the 3-D numerical results are slightly lower than those obtained by the very simple momentum model in the 1-D analysis.

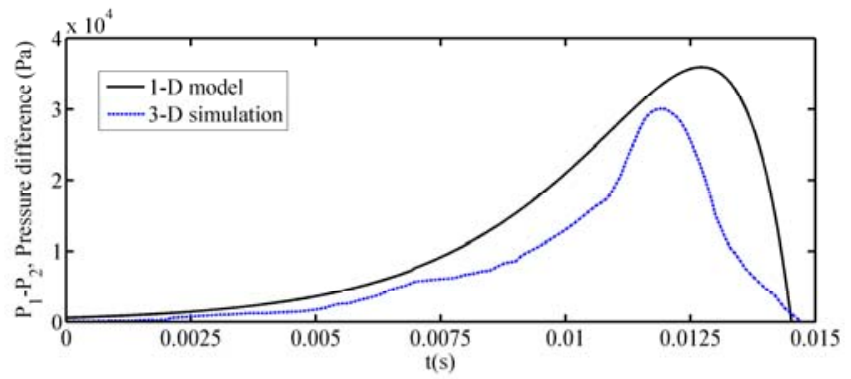

Fig. 7: Comparison of 1-D model and 3-D simulation

\section{MODIFIED 1-D MODEL WITH SATURATED} VAPOUR PROPERTIES DEPENDENT ON PRESSURE.

In section 2, qualitative effects of various parameters have been studied using simple analytical expressions obtained assuming constant vapour density. Though this model enables a quick rough estimates of the pressure drop, the deviation between its predictions and the true values will increase as the heat flux (or pressure drop) increases, due to the change in vapour density. Therefore, vapour density change with pressure and its time derivative have to be considered for accurate results.

Equations ( 1 ) and ( 12 ) are based on the usual simple balance between the heat transfer rate from the wall and the rate of evaporation, assuming constant vapour density independent of pressure.

A more realistic derivation of the equation for bubble growth rate from fundamental thermodynamic principles is as follows, although it still assumes uniform equilibrium conditions within the bubble at any instant.

Let $p, m_{v}, u_{v}, v_{v}, T_{s}(p)$ be the initial pressure, mass, internal energy, specific volume and saturation temperature of the vapour bubble respectively. For a closed system $m_{v}+d m$, let $\mathrm{dm}$ be the mass of the liquid with internal energy $u_{1}$ and specific volume $\mathrm{v}_{\mathrm{l}}$, that is converted to vapour in time $\mathrm{dt}$. Let $\mathrm{p}+\mathrm{dp}, \mathrm{m}_{\mathrm{v}}+\mathrm{dm}, \mathrm{u}_{\mathrm{v}}+\mathrm{du}_{\mathrm{v}}, \mathrm{v}_{\mathrm{v}}+\mathrm{dv}_{\mathrm{v}}, \mathrm{Ts}(\mathrm{p}+\mathrm{dp})$ be the new pressure, mass, internal energy, specific volume, and saturation temperature of the vapour bubble respectively, figure $8 \mathrm{a}-\mathrm{b}$.

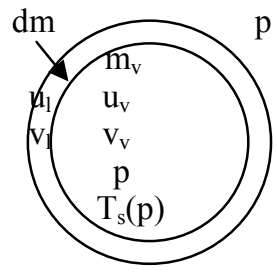

( a )

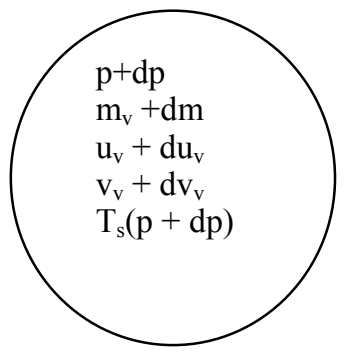

( b )
Fig. 8: Evaporative growth with variable pressure.

$$
\begin{aligned}
& \mathrm{dQ}=\mathrm{qAdt}=\mathrm{dU}+\mathrm{pdV} \\
& \mathrm{qAdt}=\left(\mathrm{m}_{\mathrm{v}}+\mathrm{dm}\right)\left(\mathrm{u}_{\mathrm{v}}+\mathrm{du}_{\mathrm{v}}\right)-\mathrm{m}_{\mathrm{v}} \mathrm{u}_{\mathrm{v}}-\mathrm{dmu}_{1} \\
& +\mathrm{p}\left[\left(\mathrm{m}_{\mathrm{v}}+\mathrm{dm}\right)\left(\mathrm{v}_{\mathrm{v}}+\mathrm{dv}_{\mathrm{v}}\right)-\mathrm{m}_{\mathrm{v}} \mathrm{v}_{\mathrm{v}}-\mathrm{dmv}_{1}\right]
\end{aligned}
$$

whence,

$$
\mathrm{qAdt}=\mathrm{m}_{\mathrm{v}}\left(\mathrm{du}_{\mathrm{v}}+\mathrm{pdv}_{\mathrm{v}}\right)+\mathrm{dm}\left(\mathrm{u}_{\mathrm{lv}}+\mathrm{pv}_{\mathrm{lv}}\right)
$$

Since $h=u+p v$

equation ( 27 ) can be written as

$$
\mathrm{qAdt}=\mathrm{m}_{\mathrm{v}}\left(\mathrm{dh}_{\mathrm{v}}-\mathrm{v}_{\mathrm{v}} \mathrm{dp}\right)+\mathrm{dm} \mathrm{h}_{\mathrm{lv}}
$$

Assuming the vapour is an ideal gas,

$$
\mathrm{dh}_{\mathrm{v}}=\mathrm{C}_{\mathrm{pv}} \mathrm{dT}_{\mathrm{s}}
$$

From Classius-Clapeyron equation, $\frac{\mathrm{dp}}{\mathrm{dT}_{\mathrm{s}}}=\frac{\mathrm{h}_{\mathrm{lv}}}{\mathrm{v}_{\mathrm{lv}} \mathrm{T}_{\mathrm{s}}}$

For $\mathrm{v}_{\mathrm{l}}<<\mathrm{v}_{\mathrm{v}}$,

$$
\frac{\mathrm{dp}}{\mathrm{dT}_{\mathrm{s}}}=\frac{\mathrm{h}_{\mathrm{lv}}}{\mathrm{v}_{\mathrm{v}} \mathrm{T}_{\mathrm{s}}}
$$

$\mathrm{dm}=\mathrm{hd}\left(\mathrm{A} \rho_{\mathrm{v}}\right)=\mathrm{h} \rho_{\mathrm{v}} \mathrm{dA}+\mathrm{hAd} \rho_{\mathrm{v}}$

Substituting ( 30), (32) and (33) in (29),

$$
\frac{\mathrm{dA}}{\mathrm{dt}}=\left(\frac{\mathrm{Aq}}{\rho_{\mathrm{v}} \mathrm{h}_{\mathrm{lv}} \mathrm{h}}\right)-\left(\frac{\mathrm{A}}{\rho_{\mathrm{v}}} \frac{\mathrm{d} \rho_{\mathrm{v}}}{\mathrm{dt}}\right)-\left(\frac{\mathrm{A}}{\rho_{\mathrm{v}} \mathrm{h}_{\mathrm{lv}}}\left(\frac{\mathrm{c}_{\mathrm{pv}} \mathrm{T}_{\mathrm{s}}}{\mathrm{h}_{\mathrm{lv}}}-1\right) \frac{\mathrm{dp}}{\mathrm{dt}}\right)
$$

Let the pressure drop across the expanding bubble be negligible compared to that across the accelerated liquid slug, then the properties, density derivative and pressure derivative in (34) correspond to the channel inlet pressure $\mathrm{p}_{1}(\mathrm{t})$.

\subsection{Partially-confined growth ( PC )}

For partially-confined growth, $A=b^{2}$. Then the bubble growth equation (34) can be written as

$$
\begin{aligned}
& \frac{\mathrm{db}}{\mathrm{dt}}=\left(\frac{\mathrm{bq}}{2 \rho_{\mathrm{v}} \mathrm{h}_{\mathrm{lv}} \mathrm{h}}\right)-\left(\frac{\mathrm{b}}{2 \rho_{\mathrm{v}}} \frac{\mathrm{d} \rho_{\mathrm{v}}}{\mathrm{dt}}\right) \\
& -\left(\frac{\mathrm{b}}{2 \rho_{\mathrm{v}} \mathrm{h}_{\mathrm{lv}}}\left(\frac{\mathrm{c}_{\mathrm{pv}} \mathrm{T}_{\mathrm{S}}}{\mathrm{h}_{\mathrm{lv}}}-1\right) \frac{\mathrm{d} \mathrm{p}_{1}}{\mathrm{dt}}\right) \\
& \mathrm{U}_{2}=\mathrm{U}_{1}+\frac{2 \mathrm{~b}}{\mathrm{w}} \frac{\mathrm{db}}{\mathrm{dt}} \\
& \frac{\mathrm{dU}}{\mathrm{dt}}=\frac{2 \mathrm{~b}}{\mathrm{w}} \frac{\mathrm{d}^{2} \mathrm{~b}}{\mathrm{dt}^{2}}+\frac{2}{\mathrm{w}}\left(\frac{\mathrm{db}}{\mathrm{dt}}\right)^{2}
\end{aligned}
$$


Using equations (6) and (7), and assuming $\rho_{\mathrm{v}}$ as constant in the third term of the expression (6), the expression for pressure drop is derived as

$$
\begin{aligned}
& \frac{\mathrm{p}_{1}-\mathrm{p}_{2}}{\rho_{1}}=\mathrm{U}_{2}^{2} \\
& +\mathrm{U}_{2}\left(-\mathrm{U}_{1}-\frac{\mathrm{db}}{\mathrm{dt}}\right)+\left(\mathrm{L}_{2}-\mathrm{U}_{1} \mathrm{t}-\mathrm{b}\right) \frac{\mathrm{dU_{2 }}}{\mathrm{dt}} \\
& +\frac{1}{2 \mathrm{w} \rho_{1}}\left[\left(\rho_{1} \mathrm{w} \frac{\mathrm{db}}{\mathrm{dt}}\right)-\left(\rho_{1}-\rho_{\mathrm{v}}\right) 2 \mathrm{~b} \frac{\mathrm{db}}{\mathrm{dt}}\right]\left(\mathrm{U}_{1}+\mathrm{U}_{2}\right) \\
& +\frac{1}{2 \mathrm{w} \rho_{1}}\left[\left(\rho_{1} \mathrm{wb}\right)-\left(\rho_{1}-\rho_{\mathrm{v}}\right) \mathrm{b}^{2}\right] \frac{\mathrm{dU} \mathrm{U}_{2}}{\mathrm{dt}}
\end{aligned}
$$

$\mathrm{p}_{2}$ is assumed constant, equal to 1 bar in the examples in this paper.

$$
\text { At time } \mathrm{t}=0, \mathrm{~b}=\mathrm{h} \text {. }
$$

Transient pressure $\mathrm{p}_{1}(\mathrm{t})$ is obtained by solving the equations (35 - 38 ) using finite difference method and taking time step $\Delta \mathrm{t}$.

Since $d \rho_{\mathrm{v}} / \mathrm{dt}$ and $d p_{1} / \mathrm{dt}$ are unknown at time $\mathrm{t}=0$, and are required for the bubble growth equation (35), expression (8) is used for obtaining $p_{1}(t=0)$. Here expression (8) is solved iteratively till $\rho_{\mathrm{v}}$ corresponds to $\mathrm{p}_{1}$. These will be $\mathrm{p}_{1}(\mathrm{t}=0)$ and $\rho_{\mathrm{v}}(\mathrm{t}=0)$, which, coupled with $\mathrm{db} / \mathrm{dt}$ from the expression (2) for $\mathrm{t}=0$, are then used for the next time step for obtaining $d p_{1} / d t$ and $\mathrm{d} \rho_{\mathrm{v}} / \mathrm{dt}$.

$$
\begin{aligned}
& \left(\frac{d p_{1}}{d t}\right)_{t=0+\Delta t}=\frac{p_{1}(t=0+\Delta t)-p_{1}(t=0)}{\Delta t} \\
& \left(\frac{d \rho_{v}}{d t}\right)_{t=0+\Delta t}=\frac{\rho_{v}(t=0+\Delta t)-\rho_{v}(t=0)}{\Delta t} \\
& b_{t=0+\Delta t}=b_{t=0}+\Delta t\left(\frac{d b}{d t}\right)_{t=0}
\end{aligned}
$$

Since $\mathrm{p}_{1}(\mathrm{t}=0+\Delta \mathrm{t})$ and $\rho_{\mathrm{v}}(\mathrm{t}=0+\Delta \mathrm{t})$ are unknowns in (40) and (41) respectively, transient pressure $p_{1}(t=0+\Delta t)$ is obtained by solving the equations ( 35-38) iteratively using finite difference technique. Similar procedure is followed for the subsequent time steps till the value of $b$ reaches $w$. This time is the confinement time, $\mathrm{t}_{\mathrm{c}}$.

\subsection{Fully-confined growth ( FC )}

For fully-confined growth, $\mathrm{A}=\mathrm{wz}$.

Then the bubble growth equation (34) can be written as

$$
\frac{d z}{d t}=\left(\frac{z q}{\rho_{v} h_{l v} h}\right)-\left(\frac{z}{\rho_{v}} \frac{d \rho_{v}}{d t}\right)-\left(\frac{z}{\rho_{v} h_{l v}}\left(\frac{c_{p v} T_{S}}{h_{l v}}-1\right) \frac{d p_{1}}{d t}\right)
$$

$$
\begin{aligned}
& \mathrm{U}_{2}=\mathrm{U}_{1}+\frac{\mathrm{dz}}{\mathrm{dt}} \\
& \frac{\mathrm{dU}_{2}}{\mathrm{dt}}=\frac{\mathrm{d}^{2} \mathrm{z}}{\mathrm{dt}^{2}}
\end{aligned}
$$

Using the expressions (16) and (7), and assuming $\rho_{\mathrm{v}}$ as constant in the third term of the expression (16), the expression for pressure drop is derived as

$$
\begin{aligned}
& \frac{p_{1}-p_{2}}{\rho_{1}}=\left(L_{2}-U_{1} t-z\right) \frac{d U_{2}}{d t} \\
& +\frac{\rho_{\mathrm{v}}}{\rho_{1}}\left(\frac{z}{2}\right) \frac{d U_{2}}{d t}+\frac{\rho_{\mathrm{v}}}{\rho_{1}}\left(\frac{U_{1}+U_{2}}{2}\right) \frac{d z}{d t}
\end{aligned}
$$

At time $\mathrm{t}=\mathrm{t}_{\mathrm{c}}, \mathrm{z}=\mathrm{w}$. The transient pressure $\mathrm{p}_{1}(\mathrm{t})$ is obtained by solving the equations (43-46) using a finite difference method, and in the same way as described for partially-confined growth.

For linking partially-confined growth and fully-confined growth, the following procedure was used.

Let $i_{c}$ be the time step at which $b$ reaches $w$ in partiallyconfined growth. Let $j_{c}$ be the time step at which fully-confined growth starts. Here $\mathrm{i}_{\mathrm{c}}=\mathrm{j}_{\mathrm{c}} \cdot \mathrm{dp}_{\mathrm{l}} / \mathrm{dt}$ and corresponding $\mathrm{d} \rho_{\mathrm{v}} / \mathrm{dt}$ at $\mathrm{j}_{\mathrm{c}}$ are obtained by using $p_{1}\left(i_{c}-1\right)$ and $p_{1}\left(j_{c}\right)$. Since $p_{1}\left(j_{c}\right)$ and $\rho_{\mathrm{v}}\left(\mathrm{j}_{\mathrm{c}}\right)$ are unknowns, $\mathrm{p}_{1}\left(\mathrm{j}_{\mathrm{c}}\right)$ and the corresponding $\rho_{\mathrm{v}}\left(\mathrm{j}_{\mathrm{c}}\right)$ are obtained by solving the equations (43-46) iteratively using finite difference technique. Similar procedure was followed for the subsequent time steps till the downstream end of the bubble, $x_{d}$, reaches the channel outlet.

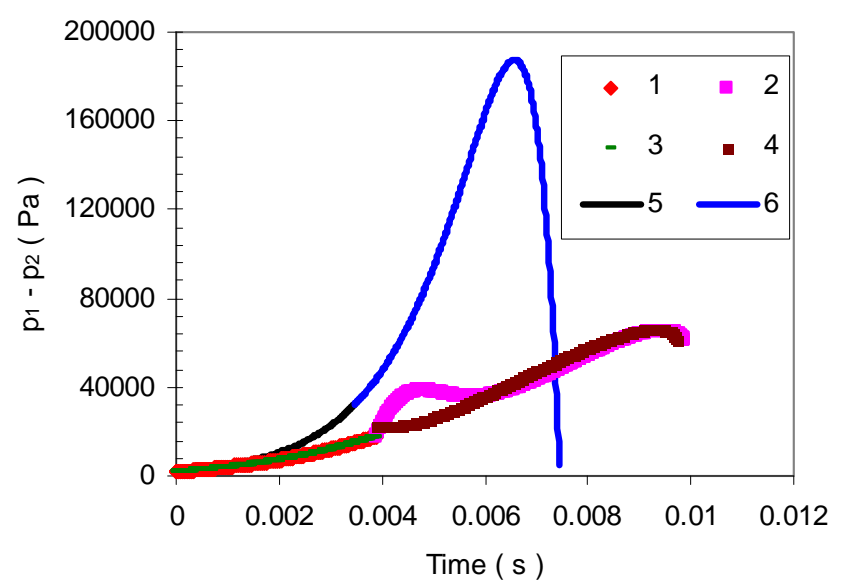

Fig. 9: Transient pressure drop for different cases. $\mathrm{L}_{1}=0 \mathrm{~mm}, \mathrm{~L}_{2}=40 \mathrm{~mm}, \mathrm{q}=400 \mathrm{~kW} / \mathrm{m}^{2}, \mathrm{U}_{1}=0.7$ $\mathrm{m} / \mathrm{s}, \mathrm{w}=1.5 \mathrm{~mm}, \mathrm{~h}=0.38 \mathrm{~mm}$.

1, 2: PC and FC with the modified model, and linking $\mathrm{PC}$ and $\mathrm{FC}$ at the transition.

3, 4: PC and FC with the modified model, and without linking $\mathrm{PC}$ and $\mathrm{FC}$ at the transition.

5, 6: PC and FC for constant vapour density $\left(\mathrm{p}_{2}\right)$. 
Figure 9 shows the transient pressure drop for water with the modified model for $400 \mathrm{~kW} / \mathrm{m}^{2}$. Here, $\rho_{\mathrm{v}}, \mathrm{T}_{\mathrm{s}}$ and $\mathrm{h}_{\mathrm{lv}}$ corresponding to $\mathrm{p}_{1}$ are evaluated from the expressions obtained by curve-fitting the data from property tables. $c_{p v}$ for water vapour is taken as constant, equal to $2.076 \mathrm{~kJ} / \mathrm{kg} \mathrm{K}$ (equal to the ideal gas value). The peak pressure drop obtained with the modified model is almost one-third of that obtained with constant vapour density and occurs later in bubble growth. The change of vapour density with the pressure and the density derivative term in the bubble growth equation are mainly responsible for this variation. When the bubble downstream end reaches the channel outlet, the pressure drop is about 60 $\mathrm{kPa}$, unlike the constant vapour density case, wherein the pressure decreases rapidly. This is because, as the pressure starts decreasing sharply after reaching the peak, the vapor density derivative becomes a high negative value and the whole density derivative term becomes a huge positive value as there is negative sign for this term in the expression for bubble growth equation (43), and this results in a very high $\mathrm{dU}_{2} / \mathrm{dt}$, making the second term in the expression (46) a very high value, and more than the decrease in the first term in the same expression, and hence the total pressure drop is about $60 \mathrm{kPa}$ at this point, which is basically the pressure drop across the bubble. Here the model stops when the downstream end of the bubble reaches the channel outlet but, as the bubble passes through the channel outlet, the pressure drop is expected to go down to zero as $\mathrm{z}$ decreases to zero, no matter what $\mathrm{dU}_{2} / \mathrm{dt}$ is.

With PC-FC linking, as described in the paragraph preceding figure 9 , there is a rise in the pressure drop following confinement, and then a decrease before increasing again. Without linking, i.e, for $\mathrm{FC}$, at $\mathrm{t}=\mathrm{t}_{\mathrm{c}}$, constant vapour density ( corresponding to pressure $\left.\mathrm{p}_{1}(\mathrm{t})\right)$ expression as given in the section 2.2 was used, and this resulted in a sharp jump ( or discontinuity) as shown in figure 9. This shows the sensitiveness of the initial condition ( or transition condition) for fully-confined growth. Future study is aimed at working out an appropriate mechanism ( or condition) for transition from partially-confined to fully-confined growth, with inputs from the experimental observations.

For the modified model, time steps $(\Delta \mathrm{t})$ of $10^{-5}, 10^{-6}$ and $10^{-7}$ $s$ were used. The difference between the results obtained by using $10^{-5} \mathrm{~s}$ and $10^{-6} \mathrm{~s}$ is about $1 \%$ and that between $10^{-6} \mathrm{~s}$ and $10^{-7} \mathrm{~s}$ is about $0.2 \%$. During the time when there is a sharp change of pressure ( or a very high pressure derivative) as the bubble downstream end approaches the channel outlet, time step of $10^{-8} \mathrm{~s}$ was used.

The problem of achieving a smooth transition from unconfined (equivalent to partially confined) growth to fully confined growth in a circular tube in models that include the dependence of vapour density on pressure was recognised and discussed in $[8,11]$. Localised experimental measurements of pressure are required to determine whether the transition really is smooth.

Here the growth model with constant heat flux eliminates the second cause of feedback between pressure changes and evaporation rates, the effect of changes in saturation temperature on $\mathrm{q}(\mathrm{t})$, e.g. for conditions of constant wall superheat. This will also be a part of the future study.

\section{CONCLUSIONS}

A simple 1-D model with constant properties for studying the qualitative effect of various parameters such as the location of the nucleation site, heat flux, inlet velocity and channel cross-section dimension on the transient pressure drop in partially-confined and fully-confined bubble growth stages has been presented. A 3-D numerical simulation based on the analytical bubble volume has been performed with FLUENT 6. Transient pressures obtained by 3-D numerical method agree reasonably well with those obtained by the 1-D model, though the former gives slightly lower values than those obtained by the 1-D model.

A modified 1-D model with variable properties has also been presented for accurate estimation of the transient pressure drop. More study is required on linking the partially-confined growth to the fully-confined growth. More complicated conditions such as variable nucleation frequencies and multiple confined bubbles along the channel will be implemented in the model later.

\section{ACKNOWLEDGEMENT}

This work is supported by the UK Engineering and Physical Sciences Research Council (EPSRC) under grants EP/D500095/1 and EP/D500125/1.

\section{REFERENCES}

1. Y.Q. Zu, S. Gedupudi, Y.Y Yan, T.G. Karayiannis, D.B.R. Kenning, Numerical simulation and experimental observations of confined bubble growth during flow boiling in a mini-micro channel with a rectangular crosssection of high aspect ratio, ICNMM2009-82118.

2. P.R. Bobboli, P. Kew, D McNeil, Heriot-Watt University, private communication, 2008.

3. D. Bogojevic, K. Sefiane, J. Christy, Edinburgh University, private communication, 2008.

4. P.A. Kew and K. Cornwell, On pressure fluctuations during boiling in narrow channels, Proc. 2nd European Thermal Sciences and 14th UIT National Heat Transfer Conf., Rome, vol. 3, pp. 1323-1327, 1996.

5. D.B.R. Kenning and Y. Yan, Saturated flow boiling of water in a narrow channel: experimental investigation of local phenomena, IChemE Trans. A, Chem. Eng. Res. and Design, vol. 79, pp. 425-436, 2001.

6. J.R. Thome, V. Dupont and A.M. Jacobi, Heat transfer model for evaporation in microchannels, Part I: Presentation of the model, Int. J. Heat Mass Transfer, vol. 47, pp. 3375-3385, 2004.

7. M.B. Shafii, A. Faghri and Y. Zhang, Thermal modelling of unlooped and looped pulsating heat pipes, J. Heat Transfer, vol. 123, pp. 1159-1172, 2001.

8. D.B.R. Kenning, D.S. Wen, K.S. Das, and S.K. Wilson, Confined growth of a vapour bubble in a capillary tube at initially uniform superheat: experiments and modelling, Int. J. Heat Mass Transfer, vol. 49, pp. 4653-4671, 2006.

9. A.J. Robinson and R.L Judd, The dynamics of spherical bubble growth, Int. J. Heat Mass Transfer vol. 47, pp.51015113, 2004.

10. S.G. Kandlikar, Nucleation characteristics and stability considerations during flow boiling in microchannels, 
Experimental Thermal and Fluid Science, vol. 30, pp. 441447, 2006.

11. D.S. Wen, K.S. Das, S.K. Wilson and D.B.R. Kenning, Initiation and growth of confined vapour bubbles in microchannels, 9th UK National Heat Transfer Conference, Manchester 5-6 September 2005.

12. C.W. Hirt, B.D Nichols, Volume of fluids (VOF) method for the dynamics of free boundaries, J. Comput. Phys, vol. 39, pp.201-225, 1981. 